\title{
Ética tau y utopía en Aristóteles
}

\author{
Víctor Hugo Méndez
}

\section{Planteamiento del problema y estado de la cuestión}

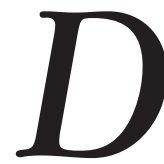
e senectute fue escrito entre los años 45 y 44 antes de Cristo. Más de dos mil años después otro intelectual de la península itálica redactó una obra con este título donde atribuye al arpinate la paternidad del género filosófico "sobre la vejez". ${ }^{1}$ A hora bien, el juicio de Norberto Bobbio sobre Cicerón genera más de una interrogante. ¿Acaso los filósofos griegos dejaron de reflexionar sobre las edades de la vida en general y sobre la vejez en particular? Si la respuesta fuera afirmativa resultaría una laguna en la filosofía griega que se vería profundizada por el hecho de que la épica y la lírica arcaicas, no menos que las tragedias clásicas, abundaron sobre el tema. Si la respuesta fuera negativa no decrecería ni un adarme el mérito del autor del Catón el mayor; pero se podría reprochar a los filósofos griegos cierta presbicia que no afectó la visión de los poetas y dramaturgos que los antecedieron y de los filósofos que los sucedieron.

El propósito de la presente comunicación se restringe a ilustrar la existencia de una reflexión filosófica sobre las edades de la vida en Aristóteles. He denominado "ética tau" a esta área de la filosofía política y moral; postulo que sin ella resulta arbitrariamente mutilada la continuidad crítica que se registra entre los discípulos de Sócrates y otros de los escritores griegos tradicionalmente excluidos del ámbito de la filosofía. ¿Pero qué es la ética tau?

\section{Éticas con theta y ética con tau}

En el libro segundo de la Ética eudemia se afirma que: "El carácter moral (êthos) se desarrolla como su nombre lo indica, por obra de la costumbre

${ }^{1}$ Cf. Norberto Bobbio, De senectute. Trad. de Esther Benítez. Madrid, Taurus, 1997, p. 23. 
(ethos)"2 El êthos con eta -morada, habitación, carácter, manera de ser, moral- ${ }^{3}$ y el ethos con épsilon -costumbre, hábito o uso- se hayan relacionados. Pero también están vinculados -sin que esto implique juicio alguno sobre la etimología- a etos con tau, esto es, año.

Entiendo por "ética tau" la concepción antropológica que plantea que tanto el "carácter moral" como la "costumbre" de un ser humano no resultan completamente ajenos al número del año en que vive, razón por la cual el alcanzar cierto rango de edad resulta condición necesaria, pero no suficiente, de la madurez a él correspondiente. Y dicha antropología filosófica fue postulada por los líricos arcaicos antes que por los filósofos clásicos.

\section{Antecedentes de la filosofía clásica en la lírica arcaica: el pensamiento antropológico de Solón}

La filosofía no heredó de Atenea el nacer madura, y completamente armada, de la cabeza de su padre. El discurso filosófico se vio en la necesidad de tomar prestadas categorías del derecho preexistente y la religión popular. El vínculo entre literatura y filosofía no fue menor. ¿Acaso algunos presocráticos, como Jonófanes, no son ciudadanos de las antologías literarias y filosóficas al mismo tiempo? Lo cierto es que cuando los presocráticos, de acuerdo con lo expuesto en el libro alpha de la Metafísica, se encontraban abocados al estudio de la phýsis, la lírica arcaica respondía a la necesidad de expresar "estados de ánimo individuales". ‘ ¿Y qué otra reflexión resulta más imperiosa que la relativa a la propia vida, a su desarrollo y su ineluctable final?

Uno de los sistemas de edades más difundido a lo largo y ancho del mundo grecorromano, aunque claramente no el único, fue el de Solón. ${ }^{5}$ El fragmento

${ }^{2}$ Aristóteles, Ética eudemia. Introd., trad. y notas de Antonio Gómez Robledo. México, UNAM, 1994, 1220a 39-1220b 1. (Bibliotheca scriptorum graecorum et romanorum mexicana). Wisse observa que el término êthos es utilizado por Aristóteles en un sentido restringido -cualidades morales- en la Poética y en la Ética nicomáquea, mientras que es empleado en un sentido más amplio - popular- en Retórica (cf. Jakob Wisse, Ethos \& pathos from Aristotle to Cicero. Ámsterdam, Adolf M. Publisher, 1989, p. 3). Esta precisión no acarrea consecuencia alguna para los propósitos del presente trabajo, por lo que será soslayada.

${ }^{3}$ Concepto recurrente en la literatura hipocrática antes que en la aristotélica (cf. Jackie Pigeaud, "Nature et culture dans l'Ethique à Nicomaque d'Aristote", en Helmantica L, 1999, 151-153, pp. 645-646).

${ }^{4} C f$. Rubén Bonifaz Nuño, "Píndaro y las leyes del mercado. Apéndice: poemas de Mimnermo, Solón, Jenófanes, Focílides y Teognis, aludidos en el texto de Píndaro y en el inciso 'Píndaro y la lírica'”, en Noua Tellus 20, 2002, 2, p. 15.

${ }^{5} \mathrm{Cf}$. Solón de Atenas, fragmento 27, en M. L. West, ed., Iambi et elegi graeci ante 
diecinueve de este personaje es denominado por Mercedes Vílchez, "poema sobre las edades de la vida". ${ }^{6}$ El padre de la democracia divide la vida humana en ciclos de siete años. Un esquema simplificador podría ser el siguiente:

\begin{tabular}{ccl}
\hline Hebdómada & Años & \multicolumn{1}{c}{ Característica } \\
\hline 1 & $1-7$ & Dentición \\
2 & $8-14$ & Pubertad \\
3 & $15-21$ & Barba \\
4 & $22-28$ & Plenitud física \\
5 & $29-35$ & Procreación \\
6 & $36-42$ & Consolidación de la mente \\
7 & $43-49$ & Plenitud mental y verbal \\
8 & $50-56$ & Continuidad de facultades con ligera \\
9 & $57-63$ & disminución \\
& & Límite natural de la vida \\
\hline
\end{tabular}

Cabe aclarar que aunque Solón considere que a los setenta años resulta factible aceptar que se ha completado un ciclo vital, él, a diferencia de Mimnermo, preferiría vivir incluso hasta los ochenta años. Por otra parte, resulta evidente que se trata de una cronología masculina. El inicio de la procreación a los treinta y cinco años resultaría tardío para una mujer dentro de los marcos culturales arcaicos, ello con independencia de las posibilidades fisiológicas reales de la especie. Sea como fuere, pueden distinguirse dos ciclos bien definidos: el físico y el intelectual. La plenitud del ciclo físico se conquista en la cuarta hebdómada, que resulta el término medio de una hebdómada mayor. El cuatro ocupa el lugar central entre siete números y representa la cima de la fuerza física aunada a la virtud masculina, de acuerdo con Solón.

alexandrum cantati. II. Callinus, Mimnermus, Semonides, Solon, Tyrtaeus, Minora Adespota. Oxford, Universidad de Oxford, 1972, pp. 119-145; Alicia Esteban Santos, "Estructura y estilo en los fragmentos de Mimnermo sobre la vejez", en Estudios Clási$\cos , 1985$, pp. 21-32; Hortencia Dora Larrañaga de Bullones, "Un anciano en la guerra de Troya", en Estudios Clásicos, 24, 1994, pp. 155-185; M. Meulder, "Platon peintre des âges de la vie humaine (République VIII, 544a IX, 580c)", en L'antiquité classique LX, 1991, pp. 102-129; Guillermo Ríos Bonilla, "Un acercamiento a la poesía de Solón de Atenas", en Noua Tellus 20, 2002, 2, pp. 51-100, y Fabio Stock, "Catone e le eta della vita”, en Rivista de Cultura Classica e Medioevale 33, 1991, 1, pp. 29-36.

${ }^{6} \mathrm{Cf}$. Mercedes Vílchez, "Sobre los periodos de la vida humana en la lírica arcaica y la tragedia griega”, en Emerita LI, 1983, 1, p. 67. 
Ciclo físico:

\begin{tabular}{|l|l|l|l|l|l|l|}
\hline & & & 4 & & & \\
\hline & & 3 & & 5 & & \\
\hline & 2 & & & & 6 & \\
\hline 1 & & & & & & 7 \\
\hline
\end{tabular}

Notablemente el ciclo intelectual requiere una doble fase preparatoria y, en consonancia, su plenitud dura el doble del tiempo que el ciclo físico.

Ciclo glotointelectual:

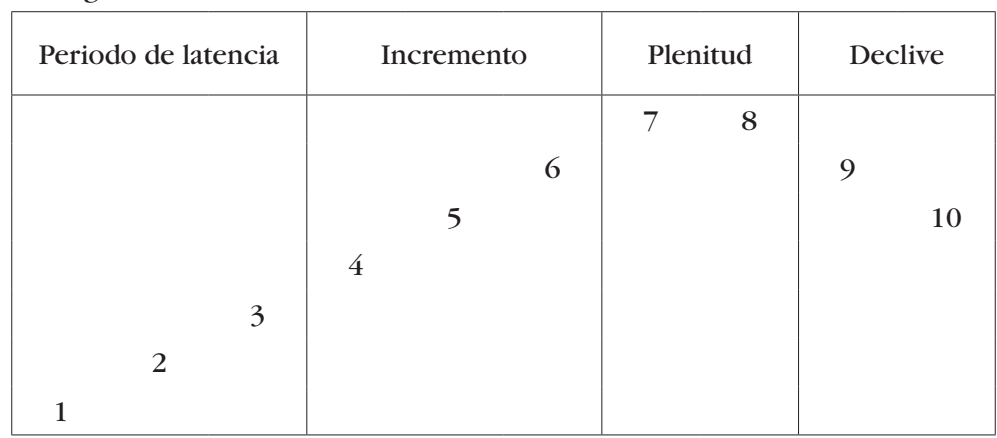

Lo que he llamado el ciclo intelectual de la vida se caracteriza por el desarrollo de facultades glotointelectuales. El órgano físico de la lengua se vincula con el pensamiento y la sabiduría. La mente se consolida en la sexta hebdómada. Antes de los treinta y seis años dicha facultad se encuentra imperfecta; pero una vez superada tal edad se libera de sus impedimentos. El ciclo de los treinta y seis a los cuarenta y dos da lugar a que se perfeccione la mente del hombre.

El mejor momento de la mente humana se registra a lo largo de la séptima y octava hebdómada. El corazón de tal edad no deja de ser significativo y será fundamental en filósofos posteriores: cuarenta y nueve años. El griego que puede aspirar a ser agathós no puede ser un infante, pero tampoco es frecuente que se trate de un presbýtes. ${ }^{7}$ ¿Será casual que el momento óptimo del sistema de Solón ocurra cuando se multiplica siete por siete?

El noveno ciclo, de los cincuenta y siete a los sesenta y tres, ya en plena senectud y declive físico, no pierde completamente el vigor glotointelectual. Lo contrario es la verdad. La presbicia agudiza la visión y permite "la máxima virtud de palabra y sabiduría".

${ }^{7}$ Cf. Armando R. Poratti, El pensamiento antiguo y su sombra. Buenos Aires, Eudeba, 2000, p. 105. 
Un esquema simplificado de las facultades glotointelectuales podría ser el siguiente:

\begin{tabular}{ccccc}
\hline Hebdómada & $\begin{array}{c}\text { Facultad } \\
\text { intelectual }\end{array}$ & $\begin{array}{c}\text { Facultad } \\
\text { lingüística }\end{array}$ & $\begin{array}{c}\text { Facultad } \\
\text { intelectual }\end{array}$ & Años \\
\hline 6 & $\mathrm{x}$ & & & $36-42$ \\
7 & $\mathrm{x}$ & $\mathrm{x}$ & & $43-49$ \\
8 & $\mathrm{x}$ & $\mathrm{x}$ & & $50-56$ \\
9 & & $\mathrm{x}$ & $\mathrm{x}$ & $57-63$ \\
\hline
\end{tabular}

El estagirita no soslaya esta herencia conceptual ni la acepta acríticamente. ¿Acaso no niega expresamente que la "edad" sea "causa" de la conducta? Así es, por lo que conviene iniciar con el tratamiento del concepto causa en la ética aristotélica.

\section{Causa e influencia en la ética aristotélica}

El concepto causa resulta central en la epistemología ${ }^{8}$ y en la metafísica ${ }^{9}$ de Aristóteles. ¿Hay lugar para él en la ética? Es verdad que las dimensiones prác-

\footnotetext{
${ }^{8}$ Suzanne Mansión observa que la ciencia aristotélica incluye entre sus características ser conocimiento causal (cf. Suzanne Mansión, Le jugement d'existence chez Aristote. 2a. ed. Lovaina, Éditions de L'Institut Superieur de Philosophie, 1976, pp. 18-42).

Mauricio Beuchot, por su parte, acota: "ya que la noción clave de la explicación es la fundamentación, y la fundamentación se realiza mediante las causas, la ciencia es para Aristóteles un saber por las causas, un saber causal. En cuanto al conocimiento por la causa, Aristóteles señala dos cosas: a) se debe conocer la causa de la cosa, pero esto queda aún en el aspecto potencial o virtual; por esto $b$ ) se debe conocer también que la causa es justamente causa de la cosa, esto es, conocer la aplicación de la causa a su efecto, lo cual es conocerla de manera actual y formal [...] Las causas, en el orden ontológico, son principios del ser; en el orden lógico, son principios del conocer. Como los principios demostrativos son los que rigen el proceso de la ciencia, y como los principios demostrativos surgen por abstracción a partir de las causas, la ciencia es conocimiento causal. Ahora bien, la causa da razón del efecto, fenómeno o cosa. Dado este carácter de razón que le pertenece, la causa es principio de universalidad (conceptualización) y principio de argumentación (demostración). Por eso, ya que la causa da razón, es el núcleo de la explicación. Las causas son explicativas porque justifican, fundamentan, dan 'la razón suficiente'. Y unifican, fundamentan, explican lo múltiple, lo que deviene y no exhibe de inmediato su inteligibilidad (Mauricio Beuchot, Ensayos marginales sobre Aristóteles. México, UNAM, 1985, pp. 49-50).

${ }^{9} \mathrm{Cf}$. Jaime Casals y Jesús Hernández Reynés, "A Note on the Use of Aitia and Aition in the Metaphysics of Aristotle", en Rivista de Cultura Classica e Medioevale 37, 1995, 1, pp. 89-96. Mauricio Beuchot, por su parte, acota que "[...] la noción de causa, el principio
} 
ticas de esta disciplina no exigen invariablemente "explicaciones causales". ${ }^{10}$ La teoría tetracausal no desempeña ninguna función fundamental en la Ética nicomáquea. Sin embargo, el corpus aristotelicum alude a otras explicaciones diferentes a las tetracausales. ${ }^{11} \mathrm{Y}$ ya ha sido demostrado que existen conceptos que "permean" el sistema filosófico en cuestión, pudiéndose encontrar tanto en la Metafísica como en la Poética o la Retórica. ${ }^{12}$ En el libro primero de la Retórica no dejan de ser mencionadas las siete causas de la acción humana:

[...] todas cuantas cosas se hacen, en necesidad que las hagan por siete causas; por fortuna, por naturaleza, por fuerza, por costumbre, por razonamiento, por enojo, por concupiscencia. Y el distinguir, además, las cosas que se hacen según la edad o hábitos o algunas otras cosas, es superfluo. Pues si ha ocurrido a los jóvenes ser iracundos o concupiscibles, no por la juventud hacen tales cosas, sino por ira y concupiscencia. $^{13}$

Estas siete causas se subdividen a su vez en las que se realizan por sí mismas y las que se llevan a cabo no por sí mismas:

Todos, en efecto, hacen todas las cosas; unas, no por sí mismos; otras, por sí mismos. Ahora bien, de las que no por sí mismos, hacen las unas por fortuna, las otras, por necesidad y de las que por necesidad, unas a fuerza, otras por naturaleza; de manera que todas cuantas no por sí mismos hacen, unas por fortuna, otras por naturaleza, otras a fuerza. Pero cuantas por sí mismos, y de las cuales son ellos causantes,

de causalidad y los diferentes géneros de causa son un punto central en la metafísica aristotélica. De alguna manera puede decirse que toda ella está basada en la perspectiva causal del universo. La ciencia es conocimiento por las causas, y la sabiduría metafísica es eminentemente causal. Define y demuestra, proporcionalmente, según todas ellas. Por eso, debido a la mala comprensión que de la causalidad han tenido la ciencia y la filosofía modernas, en la actualidad es tan mal comprendida la metafísica del estagirita" (M. Beuchot, op. cit., p. 160).

${ }^{10} \mathrm{Cf}$. Héctor Zagal Arreguín, Horismós, syllogismós, asápheia. El problema de la obscuridad en Aristóteles. Pamplona, Cuadernos de Anuario Filosófico, 2002.

${ }^{11}$ Nadie deja de reconocer que "La" teoría aristotélica de las causas es la desarrollada en la Metafísica ( $c f$. José Trindade Santos, "A filosofia como actualização da forma do saber (Aristóteles, Metafísica, A1-3)", en Kléos 4, 2000, p. 49).

${ }^{12} C f$. Luigi Senzasono, "El concepto de 'cumplimiento' en la Poética y en la Retórica de Aristóteles en relación con la Metafísica", en Helena Beristáin, comp., El horizonte interdisciplinario de la retórica. México, UNAM, 2001, p. 63.

13 Aristóteles, Retórica. Introd., trad. y notas de Arturo Ramírez Trejo. México, UNAM, 2002, 1369a 5-11. (Bibliotheca scriptorum graecorum et romanorum mexicana) 
unas por costumbre, otras por apetito; unas por apetito razonable, otras por irracional. ${ }^{14}$

Así pues, "por sí mismos" quedan:

1) Costumbre $y$

\begin{tabular}{l|l|l}
-apetito & razonable \\
& irracional: & 2) Ira \\
& 3) Concupiscencia
\end{tabular}

Mientras que "no por sí mismos" resultan:
4) Fortuna ${ }^{15}$
5) Naturaleza
6) Necesidad
7) Fuerza

La definición de "ira" aparece en el capítulo segundo del libro II de la misma Retórica: "Sea, pues, la ira un impulso, con pesar, de manifiesta venganza por manifiesto menosprecio hacia uno mismo o (hacia alguna) de sus cosas, no siendo pertinente el menospreciar". ${ }^{16}$ Tres son las formas que reconoce el estagirita: desprecio, humillación y ultraje (hýbris). ${ }^{17}$

¿En qué consiste la hýbris? ${ }^{18}$ El estagirita responde: "ahora bien, insolencia es el hacer o decir cosas por las cuales hay vergüenza para el que la sufre, no para que suceda para sí algo distinto de lo que sucedió, sino para complacerse [...]"19

${ }^{14}$ Ibid., 1368b 31-1369a 3.

15 Concepto ampliamente analizado tanto en la Física como en la Metafísica ( $c f$. Aristóteles, Física. Trad. y notas de Ute Schmidt Osmanczik, introd. de Antonio Marino López. México, UNAM, 2001, 197a 5 y ss. (Bibliotheca scriptorum graecorum et romanorum mexicana); Aristóteles, Metafísica, 2a. ed. Introd., trad. y notas de Valentín García Yebra. Madrid, Gredos, 1982, 1025a 14 y ss.; Alejandro G. Vigo, "Indiferentismo ontológico y fenomenología en la Física de Aristóteles”, en Noua Tellus 20, 2002, 2, p. 129; José Luis Calvo Martínez, "La Física", en Aristóteles, Física. Trad. de J. L. Calvo Martínez. Madrid, Consejo Superior de Investigaciones Científicas, 1996, p. XLII, y V. Méndez, ¿Filantropía divina en la ética de Aristóteles? Lectura desde la hermenéutica analógica. México, UNAM, Instituto de Investigaciones Filológicas, 2002, pp. 31-35.

${ }^{16}$ Aristóteles, Retórica, 1378a 30-32.

${ }^{17}$ Ibid., 1378 b 15.

${ }^{18}$ Para un análisis detallado de este concepto véase John Chadwick, ed., Lexicographica Graeca. Contributions to the Lexicography of Ancient Greek. Oxford, Clarendon, 1996, pp. 292-297.

${ }^{19}$ Aristóteles, Retórica, 1378b 23-25. 
¿Qué origina el placer asociado a la insolencia? Un cierto sentimiento de superioridad buscado peculiarmente por los integrantes de ciertos estratos generacionales y pecuniarios: "Y es causante del placer para quienes se insolentan, el que obrando mal, piensan que ellos están más por encima (por esto los jóvenes y los ricos son insolentes; pues piensan que insolentándose están por encima)". ${ }^{20}$ Así pues, existen edades más "fácilmente movibles" que otras por ciertas pasiones. Y los jóvenes, como ya se indicó, destacan por ser movidos a la ira. ${ }^{21}$

Sucintamente, la edad quizá no sea "causa" de la conducta; pero es uno de los factores que "inciden" en ella. ${ }^{22}$ Esto queda claro tanto en los defectos como en las virtudes. Y es la phrónesis la excelencia que mejor ilustra lo que he denominado "ética tau", como se puede apreciar en las principales obras ético políticas del estagirita: Ética nicomáquea, Política y Retórica.

\section{Phrónesis y helikía}

Quizá el mejor tratamiento de la phrónesis aristotélica se ubique en el libro sexto de la Ética nicomáquea. Las virtudes intelectuales o dianoéticas son abordadas en el libro VI. ${ }^{23}$ Suman cinco: intuición (nô̂s), sabiduría (sophía), ciencia (epistéme), prudencia (phrónesis) ${ }^{24}$ y arte (tékhne). La prudencia a su vez requiere de ciertas "virtudes intelectuales menores", ${ }^{25}$ como las denomina Caiani: buen consejo (euboulía), vivacidad del espíritu (anchínoia), ${ }^{26}$ comprensión (sýnesis), penetración (eusynesía), consideración (gnóme) y

${ }^{20}$ Ibid., 1378b 26-29.

${ }^{21}$ Cf. ibid., 1379a 11-30.

${ }^{22}$ Cf. Higinio Marín, La antropología aristotélica como filosofía de la cultura. Pamplona, Universidad de Navarra, 1993, p. 25.

${ }^{23}$ Se trata de "estados del alma" cuyo efecto consiste en el encuentro de la verdad (cf. Anthony Kenny, The Aristotelian Ethics. Oxford, Clarendon Press, 1978, p. 164). No faltan los helenistas que reprochan al estagirita que su tratamiento de éstas no pase de ser "exploratorio" (cf. W. F. R. Hardie, Aristotle's Ethical Theory. 2a. ed. Oxford, Clarendon, 1980, p. 221 y Antonio Gómez Robledo, "La sabiduría en Aristóteles", en Diánoia 3, 1957, p. 11).

${ }^{24}$ Algunos autores suelen traducir phrónesis por "practical wisdom" ( $c f$. W. D. Ross, Aristotle. Londres, Methuen, 1953, p. 217 y Vianney Décarie, "Virtud 'total', 'virtud perfecta' y kalokagathia en la Etica a Eudemo", en Brent Madison, ed., Sentido y existencia. Homenaje a Paul Ricoeur. Trad. de Enrique López Castellón. Navarra, Verbo Divino, 1976, p. 96).

${ }^{25}$ Cf. Lucia Caiani, Lettura dell' "Etica nicomachea" di Aristotele. Turín, UTET, 1998, p. 135.

${ }^{26}$ Reeve traduce agchinoia por "acumen", esto es, perspicacia ( $c f$. C. D. C. Reeve, Practices of reason. Aristotle's Nicomachean Ethics. Oxford, Clarendon, p. 78). 
habilidad. ${ }^{27}$ Ahora bien, la edad resulta condición necesaria, pero no suficiente, de la adquisición de algunas de éstas: “[...] los jóvenes llegan a ser geómetras y matemáticos [...] pero no hay uno, al parecer, que sea prudente. La causa de esto es que la prudencia versa sobre los hechos particulares, que no llegan a conocerse sino por la experiencia, y el joven no tiene experiencia, porque el mucho tiempo es el que causa la experiencia". ${ }^{28}$ ¿Qué tanta experiencia es requerida para poder aspirar a la plenitud intelectual y moral accesible a un ser humano? Aristóteles responde que "[...] la edad del mayor vigor mental, la cual, de acuerdo con lo que han dicho ciertos poetas que miden la edad por periodos de siete años, tiene lugar en la mayoría de los hombres hacia la época de los cincuenta años". ${ }^{29}$ La tensión entre sistemas rivales de medición de la vida humana es fuerte en el pensamiento mismo del estagirita. Pero lo relevante en el contexto del pensamiento utópico radica en que la plenitud intelectual no se alcanza antes de los cuarenta y nueve años. Aunque no se dice expresamente, el phrónimos o spoudâ̂os, el varón prudente y esforzado que constituye el paradigma de la ética aristotélica, vive la quinta década de su existencia. ${ }^{30}$

El príncipe de los filósofos, en una variante de su teoría del término medio, aprecia la madurez más que la niñez y la senectud. ${ }^{31}$ Sin embargo, no deja de reconocer que, a pesar de todas las objeciones que Mimnermo formuló en contra de la última etapa de la vida, la prudencia no resulta incompatible con

${ }^{27} C f$. V. Méndez, "La maldad real del rey malo (Retórica y panourgía en Platón y Aristóteles)", en Actas del I Congreso Iberoamericano de Ética y Filosofía Política. Alcalá de Henares, 2002, en prensa.

${ }^{28}$ Aristóteles, Ética nicomáquea, libro vi, 8, 1142a 12-17.

${ }^{29}$ Aristóteles, Política, vIII, 15, 1335b 32-1335b 35.

${ }^{30}$ El phrónimos es un personaje paradigmático que se distingue de las personas comunes ( $c f$. Susan K. Allard-Nelson, "Virtue in Aristotle's Rhetoric: A Metaphysical and Ethical Capacity", en Philosophy and Rhetoric, 34, 2001, 3, pp. 245-259). ¿Cómo se ingresa a este selecto grupo? Parte de la respuesta está en la edad. Un niño jamás podría ser un phrónimos aristotélico; pero sólo una minoría de cada generación madurará moralmente.

${ }^{31}$ Una más de las objeciones que se pueden formular en contra de la filosofía aristotélica radica en que ésta no reconoce plena y cabalmente la humanidad del niño (cf. Sarah Broadie, Ethics with Aristotle. Nueva York, Universidad de Oxford, 1991, p. 64 y W. W. Fortenbaugh, "The Imperfection of Young People", en Aristotle on Emotion. Londres, Duckworth, 1975, pp. 49-53). ¿Por qué? Lo propio del ser humano es la racionalidad ( $c f$. Arturo Ramírez Trejo, "Retórica de Aristóteles: tradición y verdad", en Noua Tellus 19, 2001, 1, p. 28). Y las capacidades intelectuales de los infantes se encuentran en potencia, no en acto. Ello determina que para el estagirita los niños se encuentren cercanos en algún sentido a los animales. Niños y animales no pueden acceder a la felicidad real ( $c f$. Carolina Olivares Chávez, "Los animales y el hombre en Aristóteles", en Noua Tellus 19, 2001, 1, p. 119). Sobre los "niños" en la sociedad clásica véase: M. Golden, "Pais, 'child' and 'slave'”, en L'antiquité Classique Liv, 1985, pp. 91-104. 
las canas. ¿Acaso la prudencia no constituye uno de los "rasgos pertinentes de la vejez"? Mercedes Vílchez así lo demuestra, cuando menos en la tragedia griega. ${ }^{32}$ El mismo estagirita asocia tanto algunas virtudes intelectuales como semivirtudes anexas a la prudencia con el concepto de helikía:

Por todo esto se cree que todas estas facultades son un don natural, ya que si nadie es naturalmente sabio, sí en cambio parecen tener los hombres naturalmente consideración y comprensión e intuición [práctica]. La prueba es que creemos que tales facultades acompañan a ciertas edades de la vida, es decir, que tal edad lleva consigo intuición y consideración [...] Por todo esto debemos atender a los dichos y opiniones indemostrables de los hombres de experiencia y de los ancianos o prudentes no menos que a las proposiciones demostrables, porque como tienen ojos de experiencia, ven correctamente. ${ }^{33}$

La ética aristotélica postula que la virtud se adquiere de manera "gradual". ${ }^{34}$ Y la experiencia (empeiría) resulta conditio sine qua non de la prudencia. ${ }^{35}$ ¿Qué uso da el estagirita a este andamiaje teórico? Lo emplea para desarrollar su pensamiento pedagógico no menos que para edificar su utopía.

\section{Solón en el pensamiento pedagógico de Aristóteles}

El autor de la Política, después de haber criticado generosamente lo que consideró inadecuado de las utopías anteriores y de haber ofrecido su análisis de las formas de constitución conocidas en su tiempo, dedica parte sustancial del libro VIII a "[...] determinar las condiciones con arreglo a las cuales ha de construirse la ciudad de nuestros deseos". ${ }^{36}$ El pensamiento utópico del

${ }^{32}$ Mercedes Vílchez, "Sobre los periodos de la vida humana en la lírica arcaica y la tragedia griega (II)", en Emerita, 1983, vol. 51, núm. 2, pp. 215-253. Cicerón, por su parte, afirmará que "[...] la temeridad es propia de la edad floreciente, la prudencia, de la edad que envejece" (Cicerón, De senectute vi, 20, en Catón el mayor: de la vejez. Lelio: de la amistad. Introd., trad. y notas de Julio Pimentel Álvarez. México, UNAM, 1997. (Bibliotheca scriptorum graecorum et romanorum mexicana)

${ }^{33}$ Aristóteles, Ética nicomáquea, libro VI, 11, 1143b 6-14.

${ }^{34} C f$. Ricardo Salles, "Akrasia, identidad personal y responsabilidad en Aristóteles", en Jornadas Filológicas 2000. Memoria. México, unAM, 2001, p. 328.

${ }^{35}$ Cf. S. Mansión, op. cit., p. 141.

${ }^{36}$ Aristóteles, Política, 1325b 35-37. Hay quien pondera que Aristóteles renuncia a la búsqueda de una ciudad ideal, lo cierto es que el interés del estagirita sobre esta cuestión fue sensiblemente menor que el de su maestro ( $c f$. Francisco Rodríguez Adrados, "Aristóteles en la Atenas de su tiempo", en Estudios Clásicos XXXVII, 1995, 108, p. 52). 
estagirita coincide con el de su maestro en la relevancia de la $\pi \alpha 1 \delta \varepsilon i ́ \alpha$ para la $\pi$ ó $\imath \iota$, y decreta:

Dos son las edades en que debe dividirse la educación: de los siete años hasta la pubertad, y de la pubertad a los veintiún años. Quienes dividen las edades por periodos de siete años tienen razón en general, pero hay que ajustarse a la división de la naturaleza, ya que el propósito del arte y la educación es el de colmar las deficiencias de la naturaleza. ${ }^{37}$

¿Por qué resulta tan relevante la educación a edad temprana? Porque sólo mediante ella se puede forjar al ser humano socialmente útil y moralmente virtuoso. ${ }^{38}$ ¿O de qué otra manera resultaría factible transitar del comportamiento biológico a la conducta culturalmente aceptada por la polis? ${ }^{39}$

Signo forzoso de los hábitos es el placer o la pena que acompañan a los actos. Temperante es el que se abstiene de los placeres corpóreos y en ello se complace, y disoluto el que se irrita por su privación. Valiente es el que con alegría, o al menos no con tristeza, arrostra los peligros, y cobarde el que lo hace con tristeza. La virtud moral, por tanto, está en relación con los placeres y los dolores. Por obtener placer cometemos actos ruines, y por evitar penas nos apartamos de las bellas acciones. Por lo cual, como dice Platón, es preciso que luego desde la infancia se nos guíe de tal modo que gocemos o nos contristemos como es menester, y en esto consiste la recta educación. ${ }^{40}$

Ni la democracia ateniense, la más grande de las creaciones de Solón, ni la Idea del Bien, cúspide de la metafísica platónica, satisficieron plenamente al estagirita. Sin embargo, no por ello este autor dejó de reconocer sus deudas intelectuales. ${ }^{41} \mathrm{Y}$ un pensamiento ético como el del autor de la Ética nicomáquea no podía dejar de nutrirse de las reflexiones antropológicas más lúcidas de los siglos anteriores.

${ }^{37}$ Ibid., libro VII, 15, 1336b 38-1337a 2.

${ }^{38}$ Cf. Ernest Barker, The Political Thought of Plato and Aristotle. Nueva York, Dover, 1959, p. 430.

${ }^{39}$ Cf. John Peter Anton, Aristotle's Theory of Contrariety. Londres, Routledge, 2001, p. 184 .

${ }^{40}$ Aristóteles, Ética nicomáquea, libro II, 3, 1104b 4-13.

${ }^{41}$ De hecho, la obra de Aristóteles aporta la última fuente relativamente confiable sobre el pensamiento del más conspicuo nomothetes griego ( $c f$. Adolfo J. Domínguez Monedero, Solón de Atenas. Barcelona, Crítica, 2001, p. 170). 